\title{
Space partitioning by symbiotic shrimp species cohabitating in the mushroom coral Heliofungia actiniformis at Semporna, eastern Sabah
}

Received: 12 January 2011 / Accepted: 11 February 2011/Published online: 24 February 2011

(C) The Author(s) 2011. This article is published with open access at Springerlink.com

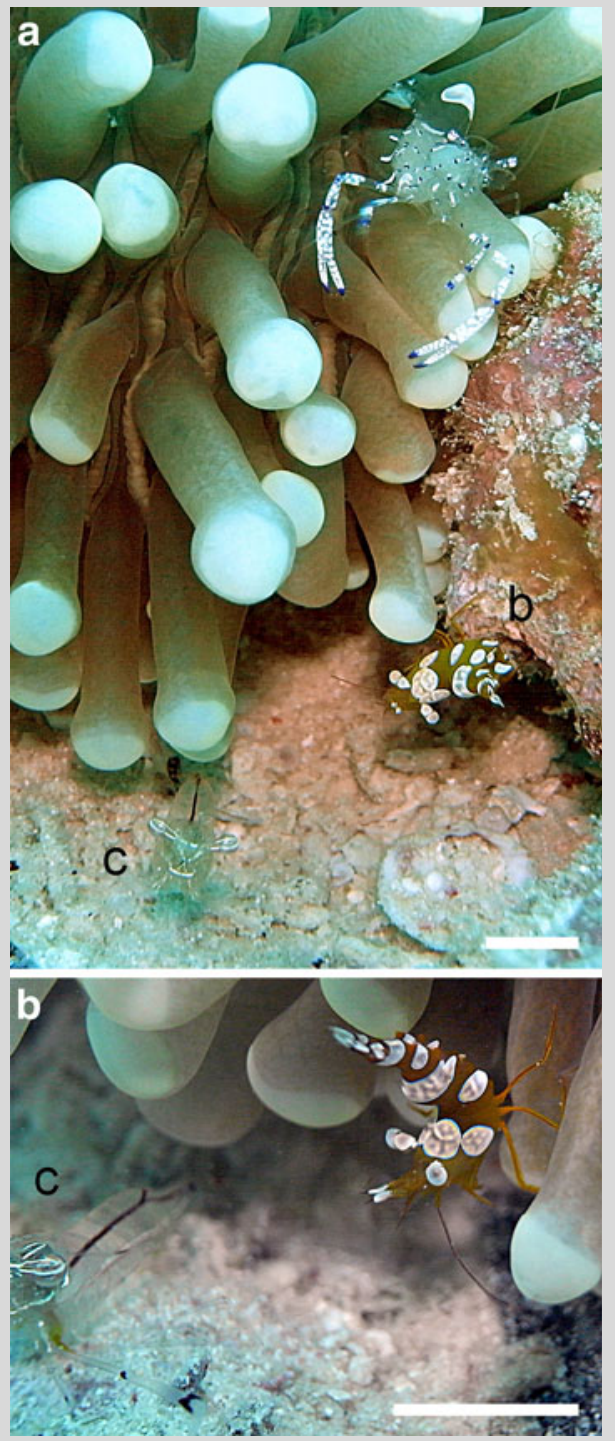

Fig. 1 A coral of Heliofungia actiniformis at Bumbun I., eastern Sabah, hosting shrimps: a Ancylomenes venustus, b Thor amboinensis and c Cuapetes tenuipes. Scale bars: $1 \mathrm{~cm}$
Many pontoniine shrimps are known as symbionts of anthozoans, such as scleractinian corals and sea anemones (Fransen 1989). So far, six shrimp species have been recorded from the solitary, free-living mushroom coral Heliofungia actiniformis (Quoy and Gaimard 1833), a coral resembling a sea anemone with long tentacles (De Grave 1998).

During the Semporna Marine Ecological Expedition (SMEE2010), eastern Sabah (Malaysia), six shrimp species were observed in association with $H$. actiniformis, including five Pontoniinae: Ancylomenes sarasvati (Okuno, 2002), A. venustus (Bruce, 1990), Cuapetes kororensis (Bruce, 1969), C. tenuipes (Borradaile, 1898), Hamopontonia corallicola (Bruce, 1970), and the hippolytid Thor amboinensis (De Man, 1888). This is a first host record for A. sarasvati. Periclimenes watamuae (Bruce, 1976), recorded by De Grave (1998), was not found in the present survey.

One coral was inhabited by A. sarasvati individuals on and between its tentacles and a pair of $C$. kororensis deep in between the tentacles. Another coral was occupied by three shrimp species, i.e., individuals of $A$. venustus on and between the tentacles (Fig. 1a), several T. amboinensis roaming on an adjacent piece of rock, the sandy substrate, and the polyp (Fig. 1b), and a C. tenuipes underneath the coral (Fig. 1c). Another $H$. actiniformis host was observed with a $C$. tenuipes in between the tentacles and one more host with a $C$. tenuipes underneath a small rock in close proximity.

This is the first record of three shrimp species in simultaneous symbiosis with a single mushroom coral host. In previous studies, individuals of just two species were found on a single individual of $H$. actiniformis (De Grave 1998). Large sea anemones have also been reported with three symbiotic shrimp species, including $T$. amboinensis (Guo et al. 1996). By occupying different parts of the host or by showing dissimilar behaviour (hiding or moving), multiple shrimp species can co-occur on the same host coral, especially if it offers sufficient hiding places.

Acknowledgments SMEE 2010 was funded through WWF Malaysia. Research permission was granted by Sabah Parks, Department of Fisheries Sabah and the Economic Planning Unit, Malaysia.

Open Access This article is distributed under the terms of the Creative Commons Attribution Noncommercial License which permits any noncommercial use, distribution, and reproduction in any medium, provided the original author(s) and source are credited.

References

De Grave S (1998) Pontoniinae (Decapoda, Caridea) associated with Heliofungia actiniformis (Scleractinia) from Hansa Bay, Papua New Guinea. Belg J Zool 128:13-22

Fransen CHJM (1989) Notes on caridean shrimps collected during the Snellius-II Expedition. I. Associates of Anthozoa. Neth J Sea Res 23:131-147

Guo CC, Hwang JS, Fautin DG (1996) Host selection by shrimps symbiotic with sea anemones: a field survey and experimental laboratory analysis. J Exp Mar Biol Ecol 202:165-176

B. W. Hoeksema $(\bowtie) \cdot$ C. H. J. M. Fransen

Department of Marine Zoology, Netherlands Centre for Biodiversity Naturalis, P.O. Box 9517, 2300 RA Leiden, The Netherlands

Coral Reefs (2011) 30:519 DOI $10.1007 / \mathrm{s} 00338-011-0736-4$ 